\title{
Integration of data mining within a Strategic Knowledge Management framework:
}

\author{
A platform for competitive advantage in the Australian mining sector
}

\author{
Sanaz Moayer \\ Murdoch University \\ Perth, Australia
}

\author{
Scott Gardner \\ Murdoch University \\ Perth, Australia
}

\begin{abstract}
In today's globally interconnected economy, knowledge is recognised as a valuable intangible asset and source of competitive advantage for firms operating in both established and emerging industries. Within these contexts Knowledge Management (KM) manifests as set of organising principles and heuristics which shape management routines, structures, technologies and cultures within organisations. When employed as an integral part of business strategy KM can blend and develop the expertise and capacity embedded in human and technological networks. This may improve processes or add value to products, services, brands and reputation. We argue that if located within a suitable strategic framework, $\mathrm{KM}$ can enable sustainable competitive advantage by mobilising the intangible value in networks to create products, processes or services with unique characteristics that are hard to substitute or replicate. Despite the promise of integrated knowledge strategies within high technology and professional service industries, there has been limited discussion of business strategies linked to Knowledge Management in traditional capital intensive industries such as mining and petroleum. Within these industries IT-centric Knowledge Management Systems (KMS) have dominated, with varying degrees of success as business analysis, process improvement and cost reduction tools.
\end{abstract}

This paper aims to explore the opportunities and benefits arising from the application of a strategic KM and Data Mining framework within the local operations of large domestic or multinational mining companies, located in Western Australia (WA). The paper presents a high level conceptual framework for integrating so called hard, ICT and soft, human systems representing the explicit and tacit knowledge embedded within broader networks of mining activity. This Strategic Knowledge Management (SKM) framework is presented as a novel first step towards improving organisational performance and realisation of the human and technological capability captured in organisational networks. The SKM framework represents a unique combination of concepts and constructs from the Strategy, Knowledge Management, Information Systems, and Data Mining literatures. It was generated from the Stage 1Literature and industry documentation review of a two stage exploratory study. Stage 2 will comprise a quantitative case based research approach employing clearly defined metrics to describe and compare SKM activity in designated mining companies.

Keywords- Knowledge Management (KM); data mining, sustainable competitive advantage; Strategic Knowledge
Management (SKM) framework; integration; hard and soft systems; Australian mining organisation.

\section{INTRODUCTION:LINKING BUSINESS STRATEGY AND KNOWLEDGE MANAGEMENT}

In a complex and challenging world, organizational success depends on the ability to configure corporate assets to reflect rapidly shifting markets and environmental conditions (Hafizi \& Nor Hayati, 2006). In recent years the competitive significance of tangible assets such as financial capital, technology or inventories has declined in the disrupted, globally interconnected markets of early $21^{\text {st }}$ century. This has led to an increased focus on strategic deployment of unique, hard to imitate, intangible assets such as expert knowledge which as a basis for sustainable competitive advantage (Hafizi \& Nor Hayati, 2006). (Shih, Chang, \& Lin, 2010).

Knowledge is actionable information which helps people to make better decisions and to be more creative in their approach to a range of problem solving activities. Many organizations seek to identify, stocks of knowledge embedded in their human, information and communication networks and link them to value adding flows, using Knowledge Management. Knowledge Management(KM) is defined by Jashapara (2011, p14) as- "The effective knowledge processes associated with exploration, exploitation and sharing of human knowledge (tacit and explicit) that use appropriate technology and cultural environments to enhance an organization's intellectual capital and performance". Knowledge Management (KM) processes help organizations to define, select, organize, distribute, and transfer information, knowledge and expertise retained in the organization's memory in an unstructured manner (Turban \& Leidner, 2008).Effective KM improves operational efficiency, enhances products and services and creates customer satisfaction (Lee, 2009). Knowledge Management has many potential benefits such as retaining expertise, capturing and sharing best practice, corporate support, improved customer service, better decision making, increased profitability and competitive advantage (Duvall, 2002). Over the past fifteen years KM has been increasingly recognised in the strategy, management and information systems literature, with senior managers treating it as a focal point for improving organizational performance, adding value to goods and services, building brands and reputation. 
While $\mathrm{KM}$ is often associated with professional services, biotechnology, IT and internet businesses, it also has significant potential for adding value and reducing costs in mining and allied industries. Mining organizations employ many skilled knowledge professionals in science, engineering, and technology, including geologists and other earth scientists. Computer scientists also have a key role in mining organizations working with managers from different functional areas to integrate and exploit the knowledge capacity of these companies (Fernandez, 2010). Employing high value knowledge workers and retaining knowledge inhouse has a strong economic justification. The migration towards Strategic Knowledge Management systems and practices is inevitable part of this process (Fernandez, 2010).

\section{CONVERTing DatA Into ACTIONABle KNOWLEDGE}

In the IT literature Data Mining (DM) is often represented uncritically as a powerful tool for knowledge discovery. As noted by (Lee, 2009) it is helpful for discovering patterns of data and creating new information. Arguably Data Mining gives organisations the ability to exceed their goals and enables decision makers to deploy the results (Noonna, 2000), for improving business performance in highly competitive environments. These statements point to the practical benefits and applications of data mining as a knowledge generation and decision support tool. However there has been little discussion in the literature of how DM processes can be integrated into dynamic business strategies supported by KM organizing principles, management routines, structures, information systems and organisational culture. Malhotra highlights the dynamic connectivity between strategy, change, human and information systems stating that- "Knowledge Management caters to the critical issues of organisational adaptation, survival, and competence in the face of increasingly discontinuous environmental change...(It) seeks a synergistic combination of the data and information processing capabilities of information technology and the creative and innovative capacity of human beings" (Malhotra 2000\&2001 in Haslinda and Sarinah 2009).

Just how to achieve these synergies between hard (technological) and soft (human) systems remains one of the central questions yet to be addressed in organisational studies. Managing the interface between people and technology within complex organisations often manifests as a 'black art' for even the most adept computer scientist or organisational psychologist. The ability to frame or ask the right questions and arrive at satisfactory answers is deeply rooted in our own worldviews. It is subject to our interpretation of KM concepts drawn from philosophy and the information, cognitive, social sciences. As observed by Liebowitz and Megbolugbe (2003) converting data into actionable information or useful knowledge in organisations is not a simple, mechanistic process. It is dependent on heuristic rules and the broader ontologies or worldviews of key actors within the system (Liebowitz \& Megbolugbe, 2003, p. 189).The Strategic Knowledge Management (SKM) framework presented in this paper (Figure 1) acknowledges this complexity while outlining key elements and broad interrelationships, which subject to further empirical investigation may advance $\mathrm{KM}$ and $\mathrm{DM}$ practice.

\section{OBJECTIVES, Scope AND Method Of THE PAPER}

The aim of this paper is to present a novel Strategic Knowledge Management (SKM) framework (Figure1), as a platform for building competitive advantage within a mining industry context. The defining characteristics and claimed benefits of Knowledge Management and Data Mining are discussed in relation to the SKM framework incorporating four related perspectives on strategic management. These characteristics have been derived from a limited review of the Strategic Management, Knowledge Management and Data Mining literatures, with relevant academic sources and reports profiling the Australian mining industry. This review of concepts and industry data has been used to produce a high level representation of strategic management and Data Mining processes applicable to the Australian based operations of large mining companies. It represents Stage 1 of two stage study combining a a high level SKM framework generated from a review of relevant strategy, KM and DM concepts with a quantitative case based research method. The SKM framework in this paper is presented for peer and industry stakeholder feedback prior to developing a detailed Stage 2 model employing hard metrics. These will be used to describe measure and compare Strategic Knowledge Management (SKM) activities displayed in three large mining organisations.

\section{Four VIEWS OF STRATEGY AND COMPETITIVE ADVANTAGE}

Strategy is the scope for an organisation to gain benefits and advantages, with available resources in a challenging environment in the long-term (Johnson, Scholes, \& Whittington, 2005). Strategic management is the art and science of formulating, implementing and evaluating functional decisions that empower the organisation to gain its goals and objectives (David, 2011). The long term performance of organisation is defined by a set of managerial decisions or strategic choices (Hunger \& Wheelen, 2003).

There a number of interrelated views of strategy identified as the basis of competitive advantage in the strategic management literature. These include: variations on Porter's (1980) economic perspective or Market-Based View (MBV); Freeman and McVea's (2001) political perspective or Stakeholder-Based View, (SBV); Barney's (1993) internal human, structural and capital asset capability perspective, or Resource-Based View (RBV); and more recently the portfolio of expertise or Knowledge-Based View (KBV) popularised by Spender (1996), Grant (1996). Both RBV and KBV have subsequently been elaborated and linked the theory of dynamic capabilities (Mouritsen, Larsen, \& Bukh, 2005).Dynamic capabilities theory focuses on the firm's ability anticipate and adapt to dynamic, discontinuous or disruptive market conditions. This is achieved when managers synergistically combine portfolios of knowledge assets with organizational learning routines, sense making and strategy to process market signals and anticipate emerging conditions (Choo, 1998). These actions serve to renew organizational structures and systems whilst generating unique assets as a basis for competitive advantage. This follows the Schumpeterian logic of competition based on "creative destruction of existing resources and novel combinations of 
new functional competences" (Pavlou and El Sawy, 2004 in Easterby-Smith and Prieto, 2008, p 236).

All four strategic perspectives and elements of dynamic capabilities theory incorporated into the SKM (Figure 1), are particularly applicable to multinational mining companies, which can exercise control over local, regional, and global markets and supply chains. The local operations of these larger companies can also develop a strong internal human resource profile and workforce capability through attractive salary packages or significant investments in workforce planning, training, information technology expertise and infrastructure. The Market-Based View focuses on achieving an attractive position within a designated industry. (Poser, 2003). It can help mining companies to exercise strategic choice and identify which factors of production should be prioritised to gain competitive advantage in specific industry structures or market segments (Porter, 1980). The Stakeholder-Based View acknowledges the political dimensions of strategy. It highlights the importance of working with constituents or stakeholders to facilitate the achievement of business goals and competitive advantage through informed decision making. It proposes that managers formulate and implement political processes that identify, classify and build productive relationships with people who have stake in the business (Freeman \& McVea, 2001); (Gardner, 2001). The ResourceBased View emphasises that organisational performance depends on internal resource configurations and capabilities including physical resources, human resources, and organisational resources (David, 2011). By extension the Knowledge-Based View is built on the logic of the ResourceBased View. It revisits many tenets of knowledge conversion and creation. It also identifies organizational learning and management routines as potential sources of competitive advantage (Jashapara, 2011). Taking the Knowledge-Based View (KBV) of strategy, knowledge is a valuable resource and basis for competitive advantage in organizations. We argue that this view is particularly applicable to the emerging knowledge and high technology sectors and the traditionally capital intensive industry sectors, such as mining and petroleum.

\section{THE AUSTRALIAN Mining INDUSTRY}

Mining is a major industry in Australia. One third of the word's mineral resources are produced in Australia (Nimmagadda \& Dreher, 2009). The Australian mining sector generated revenue of about $\$ 138.8$ billion in $2006-7$ growing to $\$ 203.9$ billion in 2011-12. Mining is expected to generate about $8.0 \%$ of Australia's GDP in 2012 with a profit forecast of $\$ 58.3$ billion. (IBIS World, 2012). These statistics indicate that the mining industry plays important role in maintaining revenue growth in Australia within a global context of economic slowdown or contraction. No other industry in Australia has gained a superior significance in economic development terms (Fernandez, 2010).

The scope of the mining industry includes all operations for extracting minerals or hydrocarbons. Coal, oil and gas, metal ore, and non-metallic mineral commodities are products of this industry (IBIS World, 2012). Exploration, drilling, production, and marketing are significant business functions in the resource industry. In recent years the major resource companies and primary contractors have increasingly recognised relationships with suppliers, customers, regulators and other stakeholders as critical determinant of firm and industry performance. According to Richards (2009), suppliers in particular can drive organisations to produce new services in different ways (Richards, 2009). The knowledge-base of suppliers is an important element to increase performance and maintain the competitive advantage of firms in the mining industry (Urzúa, 2011).

\section{DATA MINING AND ITS APPLICATION IN MINING INDUSTRIES}

Data Mining (DM) is a technique for identifying patterns and relationships between data in large databases (Lee, 2009). It also informs strategic and operational decisions in organisations through dashboards, and interrogation or scanning of relational databases. Data mining aids organisational problem solving by employing programs that can search for patterns and relationships without human intervention (Paddock \& Lemoine, 2012, p. 4). Giudici (2003, p.2) offers a more complete definition of data mining as: “ ...the process of selection, exploration, and modelling of large quantities of data to discover regularities or relations, that are at first unknown with the aim of obtaining clear and useful results for the owner of the database".

Data Mining encompasses major tasks such as data exploration, data archaeology, data pattern processing, data dredging, information harvesting, and knowledge extraction (Lee, 2009). Data mining technology is becoming a significant aspect of strategy for many organisations. It has become major component of (often complex multi-interface) enterprise decision support systems (Brusilovsky \& Brusilovskiy, 2008).

In general, business problems can be categorised as structured or unstructured. Statistical analysis is useful for overcoming structured problems and DM is often employed to deal with unstructured problems. This capability to interpret problem characteristics and dimensions makes DM potentially compatible with the human cognitive processes required to generate useful context specific, knowledge and address complex problems. This is consistent with the logic of gaining competitive advantage through unique processes, products and services that are hard to replicate. As noted by (Brusilovsky \& Brusilovskiy, 2008) the strategic strength of DM resides in the ability to deal with unstructured problems because competitors are not familiar with the characteristics of, or solutions to, these kinds of problems (Brusilovsky \& Brusilovskiy, 2008, p. 131).Data Mining clearly has the potential to deliver significant benefits if framed within broader KM enabling architecture and aligned through heuristic questioning and iteration to business goals and an unfolding strategy process. The different characteristics of KM enabling architecture are outlined in the models below. These key elements can most usefully be incorporated into the SKM framework are then briefly discussed.

\section{ReleVAnt Models Of KNOWLEDGE MANAGEMENT}

Senior managers, KM and IT specialists within the mining industry must choose an appropriate model which fits the 
strategic goals, processes and changing environment of their organisations. Table 1 below illustrates the different dimensions of knowledge, creation; individual cognition and shared learning captured in some of the more widely cited models from the KM literature: (Dalkir, 2005, pp. 49-72); (Haslinda \& Sarinah, 2009, pp. 189-196); (McAdam \& McCreedy, 1999, pp. 95-98).

The decision to incorporate any of these KM elements into an organisational Knowledge Management systems and practices is context or domain dependent. According to Sanchez and Heene (1997) organisational knowledge and learning cannot be understood from a purely (top down) strategic perspective, so organisations should also generate (bottom up) KM activities based on analysis of the context in which organisation's knowledge is applied (Sanchez \& Heene, 1997, p. 12). All the models outlined above contribute a perspective or position on the nature of knowledge, knowledge as an asset, and knowledge as a capability, knowledge enabling structures, cultures, or leadership practices germane to the SKM framework in Figure 1. However Nonaka's (1995) knowledge spiral model and Hedland and Nonaka's (1993) $\mathrm{KM}$ framework are the most pertinent to our discussion of integrating strategy, KM structures and processes, with data mining activities. These models focus on surfacing, combining and actioning tacit knowledge (based on human cognition) and explicit knowledge (repositories of data and information) to add value in organisations. This is achieved through the SECI (Socialisation, Externalisation, Combination and Internalisation), knowledge conversion process. The SECI process is in turn enabled by Ba - Nonaka and Tackeuchi's concept of a safe space (or cyberspace). This supports conversion of knowledge assets into value added products, processes or services, enabled by Information and Communication Technology (ICT) infrastructure, management and teamwork practices (Nonaka \& Takeuchi, 1995). The converted knowledge assets are simultaneously carried up through the organisational structure in a dynamic spiral to inform senior management decision making and support the strategy process. This model is most applicable within project based industries like mining which typically rely on matrixes superimposed on functional structures to align staff expertise and capacity with business requirements. We propose that SKM can overcome these limitations by using clearly articulated organising principles to drive KM and Organisational Learning (OL) activities. These are embedded in management routines, which continuously align human, and technology interactions, structures, cultural norms and values with dynamic changes in the competitive environment.

\section{TOWARDS A STRATEGIC KNOWLEDGE MANAGEMENT} (SKM) FRAMEWORK FOR THE AUSTRALIAN MINING INDUSTRY

Figure 1, below, illustrates the integration of data mining practices into a SKM framework applicable to global and Australian based mining operations. It presents a high level guide to exploiting the knowledge embedded in human and ICT networks to create process efficiencies, improve decision making and by extension, productivity for large multinational miners domiciled in Australia. SKM is premised on the idea that data mining should not be conducted in isolation from a broader KM strategy that incorporates the following elements:
1)Simultaneous application of interrelated strategic perspectives notably: The Market Based View paying attention to product, price or supply chain concerns; The Resource-Based View focusing on how to build human capability and physical asset capacity; The Stakeholder Based View concerned with building relational capital and the salient stakeholders who can affect or are affected by the goals and activities of the firm; and finally the Knowledge-Based View which emphasises the importance of managing human networks, knowledge portfolios, stocks and flows as a key determinant of organisational performance and sustainable competitive advantage. Adoption of these strategic perspectives and organisational learning processes links the firm's dynamic capabilities to KM and day to day management practices. As such SKM supports a dynamic strategy process which calibrates internal capability with changes in the external environment.

2) A knowledge enabling architecture based on reciprocal hard and soft system organising principles. This living architecture is generated from different ontological positions, heuristics, and taxonomies. Its design elements are comprised of transparent organising principles, shared goals and priorities negotiated between key internal actors representing the tension between commercial, humanistic and technologically orientated worldviews. These in turn drive management routines and practices, information and communications infrastructure design (including DM tools), organisational structure, culture and reward systems. Using iterative action learning loops these first and second order design elements are continuously re-configured to support knowledge creation and adaptability to dynamic competitive conditions.

3) Alignment mechanisms: The proposed SKM approach to action learning is consistent with Nonaka's knowledge spiral and tacit to explicit continuous knowledge conversion model. Both are generative bottom up approaches. They are aim to align individual and team behaviours with organisational structures, rewards and management routines and broader KM based strategy. This requires ongoing dialogue between DM and information systems specialists, vendors and senior managers. This is something akin to the $B a$ or a safe physical or virtual space for knowledge sharing. High trust, open protocol environments of this type is essential for effective knowledge sharing, problem solving, and identification of common ground between senior managers and IT specialists. This safe space and common ground allows for the surfacing and testing of different ontological viewpoints and creation of shared heuristics. This precedes the dialogue on shared organising principles which once agreed can lead practical discussion of how best to manage data, information and unique knowledge assets to achieve competitive advantage for the organisation.This preliminary framework will be further refined based on peer review, tested and empirically validated through application to KM and data mining systems and practices in three West Australian mining organisations.

A broad inventory of data mining tasks and Strategic Knowledge Management processes will be created for each firm as part of the process for testing the model. 


\begin{tabular}{|c|c|}
\hline Model & Features \\
\hline \multirow{2}{*}{$\begin{array}{l}\text { The von Krogh and Roos Model of } \\
\text { organisational Epistemology (Von Krogh \& } \\
\text { Roos, 1995) }\end{array}$} & Individual knowledge \\
\hline & Social knowledge \\
\hline \multirow[b]{2}{*}{$\begin{array}{l}\text { The Nonaka and Takeuchi Knowledge } \\
\text { Spiral Model (Nonaka \& Takeuchi, 1995) }\end{array}$} & Knowledge creation \\
\hline & $\begin{array}{l}\text { Knowledge conversion } \\
\text { (Socialisation, externalisation, } \\
\text { combination, internalisation), } \\
\text { ' } B a \text { ' safe space, } \\
\text { Knowledge assets. }\end{array}$ \\
\hline \multirow{8}{*}{$\begin{array}{l}\text { Hedlund and Nonaka's Knowledge } \\
\text { Management Model (Hedlund \& Nonaka, } \\
\text { 1993) }\end{array}$} & $\begin{array}{l}\text { Articulated knowledge- } \\
\text { Individual }\end{array}$ \\
\hline & $\begin{array}{l}\text { Tacit knowledge- } \\
\text { Individual }\end{array}$ \\
\hline & $\begin{array}{l}\text { Articulated knowledge- } \\
\text { Group }\end{array}$ \\
\hline & Tacit knowledge- Group \\
\hline & $\begin{array}{l}\text { Articulated knowledge- } \\
\text { Organisation }\end{array}$ \\
\hline & $\begin{array}{l}\text { Tacit knowledge- } \\
\text { Organisation }\end{array}$ \\
\hline & $\begin{array}{l}\text { Articulated knowledge- } \\
\text { Inter- Organisational } \\
\text { Domain }\end{array}$ \\
\hline & $\begin{array}{l}\text { Tacit knowledge- Inter- } \\
\text { Organisational Domain }\end{array}$ \\
\hline \multirow{3}{*}{$\begin{array}{l}\text { The Choo Sense-making KM Model (Choo, } \\
\text { 1998) }\end{array}$} & Sense making \\
\hline & Knowledge creation \\
\hline & Decision making \\
\hline \multirow{3}{*}{$\begin{array}{l}\text { The Wiig Model for Building and Using } \\
\text { Knowledge (Wiig, 1993) }\end{array}$} & Public Knowledge \\
\hline & Shared experience \\
\hline & Personal knowledge \\
\hline \multirow{4}{*}{$\begin{array}{l}\text { The Boisot knowledge category Model } \\
\text { (Boisot, 1987) }\end{array}$} & Propriety knowledge \\
\hline & Personal knowledge \\
\hline & Public knowledge \\
\hline & Common sense \\
\hline \multirow{2}{*}{$\begin{array}{l}\text { The Boisot I-Space KM Model (Boisot, } \\
\text { 1998) }\end{array}$} & Codified- Uncodified \\
\hline & Abstract- Concrete \\
\hline
\end{tabular}

\begin{tabular}{|c|c|}
\hline Model & Features \\
\hline & Diffused- Undiffused \\
\hline \multirow{5}{*}{$\begin{array}{l}\text { Skandia Intellectual Capital Model of } \\
\text { Knowledge Management (Chase, 1997); } \\
\text { (Roos \& Roos, 1997) }\end{array}$} & Equity \\
\hline & Human Capital \\
\hline & $\begin{array}{l}\text { Customer } \\
\text { Capital(Customer Base, } \\
\text { Relationsips, Potential) }\end{array}$ \\
\hline & Innovation Capital \\
\hline & Process Capital \\
\hline \multirow{4}{*}{$\begin{array}{l}\text { Demerest's Knowledge Management Model } \\
\text { (Demerest, 1997) }\end{array}$} & Knowledge construction \\
\hline & Knowledge embodiment \\
\hline & $\begin{array}{l}\text { Knowledge } \\
\text { dissemination }\end{array}$ \\
\hline & Use \\
\hline \multirow{5}{*}{$\begin{array}{l}\text { Frid's Knowledge Management Model } \\
\text { (Frid, 2003) }\end{array}$} & Knowledge Chaotic \\
\hline & Knowledge Aware \\
\hline & Knowledge Focused \\
\hline & Knowledge Managed \\
\hline & Knowledge Centric \\
\hline \multirow{4}{*}{$\begin{array}{l}\text { Stankosky and Baldanza's Knowledge } \\
\text { Management Framework (Stankosky \& } \\
\text { Baldanza, 2001) }\end{array}$} & Learning \\
\hline & Leadership \\
\hline & $\begin{array}{l}\text { Organisation, structure } \\
\& \text { culture }\end{array}$ \\
\hline & Technology \\
\hline \multirow{5}{*}{$\begin{array}{l}\text { Kogut and Zander's Knowledge } \\
\text { Management Model (Kogut \& Zander, } \\
\text { 1992) }\end{array}$} & Knowledge Creation \\
\hline & Knowledge Transfer \\
\hline & $\begin{array}{l}\text { Process \& } \\
\text { Transformation Of } \\
\text { Knowledge }\end{array}$ \\
\hline & Knowledge capabilities \\
\hline & $\begin{array}{l}\text { Individual "Unsocial } \\
\text { sociality" }\end{array}$ \\
\hline \multirow{4}{*}{$\begin{array}{l}\text { Complex Adaptive System Model of KM } \\
\text { (Bennet \& Bennet, 2004) }\end{array}$} & Creating new ideas \\
\hline & Solving problems \\
\hline & Making decisions \\
\hline & $\begin{array}{l}\text { Taking actions to } \\
\text { achieve desired results }\end{array}$ \\
\hline
\end{tabular}

Table 1: Overview of Widely Cited Knowledge Management Models

\section{CONCLUSION}

Australia is the one of the largest producer of mineral resources and the mining industry plays a significant role in national revenue growth. Finding new ways to identify and activate the knowledge capabilities embedded in human and technological networks is a critical concern for mining organisations seeking increased efficiencies, productivity and competitive advantage in Australian and global markets. The SKM framework and discussion presented in this paper represents a useful point of departure for companies pursuing this goal.

\section{REFERENCES}

[1] IBIS World. (2012, May). Retrieved from Mining in Australia: Market Research http://www.ibisworld.com.au/industry/default.aspx?indid=55

Report:

[2] Barney, J. B. (1991). Firm resources and sustained competitive advantage. Journal of Management, 17(1), 99-120.

[3] Bennet, A., \& Bennet, D. (2004). Organizational survival in the new world: the inteligent complex adaptive system. A new theoary of the firm. Burlington: MA:Elsevier Butterworth-Heinemann.

[4] Boisot, M. (1987). Information and Organizations. The Manager as Anthropologist, , Fontana/Collins, London.
[5] Boisot, M. (1998). Knowledge assets: Securing competitive advantage in the information economy. Oxford University Press, USA.

[6] Brusilovsky, D., \& Brusilovskiy, E. (2008). White Paper: Data mining: the means to competitive advantage. retreived from http://www.bisolutions.us/web/graphic/BISolutions-DATA-MININGTHE-MEANS-TO-COMPETITIVE-ADVANTAGE.pdf.

[7] Chase, R. (1997). The Knowledge based Organization: An International Survey. Journal of Knowledge Management, 1(1).

[8] Choo, C. (1998). The knowing organization. New York: Oxford University Press.

[9] Dalkir, K. (2005). Title Knowledge management in theory and practice . Amsterdam ; Boston : Elsevier/Butterworth Heinemann.

[10] David, F. R. (2011). Strategic Management concepts and cases. Prentice Hall.

[11] Demerest, M. (1997). Understanding knowledge management. Journal of long range Planing, 30(3), 374-84.

[12] Duvall, M. (2002). Knowledge Management Vendors Go Vertical. Intranet journal.

[13] Easterby-Smith, M., \& Prieto, I. M. (2008). Dynamic Capabilities and Knowledge Management: An integrative role for learning. British Journal of Management, 19, 235-249.

[14] Fernandez, M. C. (2010). Knowledge-intensive service activities in the success of the Australian mining industry. The Service Industries Journal, 30(1), 55-70. 
[15] Freeman, R., \& McVea, J. (2001). A stakeholder approach to strategic management. .

[16] Frid, R. (2003). A Common KM Framework For The Government Of Canada: Frid Framework For Enterprise Knowledge management. Canadian Institute of Knowledge Management, Ontario.

[17] Gardner, R. S. (2001, May). Stakeholder and Reputation Management as a tool for effective governance in corporatised government agencies. Journal of Contemporary Issues in Business and Government, 7(1), 2940.

[18] Grant, R. M. (1996). Toward a knowledge-based theory of the firm. Strategic Management Jurnal, 17, 109-22.

[19] Hafizi, M. A., \& Nor Hayati, A. (2006, September). KNOWLEDGE MANAGEMENT IN MALAYSIAN BANKS: A NEW PARADIGM. Journal of Knowledge Management Practice, Vol. 7, No. 3, September 2006, 7(3).

[20] Haslinda, A., \& Sarinah, A. (2009). A Review of Knowledge Management Models. The Journal of International Social Research, 2(9), 187-198.

[21] Hedlund, G., \& Nonaka, I. (1993). Models of Knowledge Management in the West and Japan. Implementing Strategic Process, Change, Learning and, 117-44.

[22] Hunger, D., \& Wheelen, T. L. (2003). Essentials of Strategic Management. Prentice Hall.

[23] Jashapara, A. (2011). Knowledge management an integrated approach (second ed.). Sydney: Prentice Hall.

[24] Johnson, G., Scholes, K., \& Whittington, R. (2005). Exploring corporate strategies (7 ed.). Financial Times Prentice Hall.

[25] Kogut, B., \& Zander, U. (1992). Knowledge of the Firm, Combinative Capabilities, and the Replication of Technology. Organization Science, 3(3), 383-97., 3(3), 383-397.

[26] Lee, M.-C. (2009, September). The Combination of Knowledge Management and Data mining with Knowledge Warehouse. International Journal of Advancements in Computing Technology, 1(1), 39-45.

[27] Liebowitz, J., \& Megbolugbe, I. (2003). A set of framework to aid the project manager in conceptualizing and implementing knowledge management initiatives. International Journal of Project Management, 21, 189-98.

[28] McAdam, R., \& McCreedy, S. (1999). A critical review of knowledge management models. The learning organization, 6(3), 91-100.

[29] Mouritsen, J., Larsen, H. T., \& Bukh, P. N. (2005). Dealing with the knowledge economy: intellectual capital versus the balanced scorecard. Journal of Intellectual Capital, 16(1).
[30] Nimmagadda, S. L., \& Dreher, H. (2009). On issues of data warehouse architectures-managing australian resources data. IEEE International Conference on Digital Ecosystems and Technologies.

[31] Nonaka, I., \& Takeuchi, H. (1995). The knowledge-creating company: How Japanese companies create the dynamics of innovation. New York: Oxford University Press.

[32] Noonna, J. (2000, Jul). Data Mining strategies. Retrieved from information management: http://www.informationmanagement.com/issues/20000701/2367-1.html?zkPrintable=true

[33] Paddock, J., \& Lemoine, K. (2012). Business Intelligence and Data Mining Review.

[34] Porter, M. E. (1980). Competitve Strategy: thechniques for Analyzing Industries and Competitors. New York: Free Press.

[35] Poser, T. B. (2003). Poser,T. B.(2003). The Impact of Corporate Venture Capital: Potentials of Competitive Advantages for the Investing Company. Germany: DUV.

[36] Richards, J. (2009). Mining, society and sustaiable world. Springer.

[37] Roos, G., \& Roos, J. (1997). Measuring your Company's Intellectual Performance. Journal of Long Range Planning,, 30(3), 413-26.

[38] Sanchez, R., \& Heene, A. (1997). Strategic learning and knowledge management. John Wiley \& Sons, Inc.

[39] Shih, K.-H., Chang, C.-J., \& Lin, B. (2010). Assessing knowledge creation and intellectual capital in banking industry. Journal of Intellectual Capital, 11(1), 74-89.

[40] Spender, J. C. (1996). Making knowledge the basis of a dynamic theory of the firm. Strategic Management Journal, 17, 45-62.

[41] Stankosky, M., \& Baldanza, C. (2001). A systems approach to engineering a KM system. Unpublished manuscript.

[42] Turban, E. D., \& Leidner, e. a. (2008). Information Technology For Management.

[43] Urzúa, O. (2011, June 29). World-class suppliers to the Mining Industry Supporting the development of a knowledge-based. Retrieved from

http://www.corfo.cl/transferenciatecnologica/PDF/Technology_Transfe r_Presentation_BHP_Billiton_Santiago_2011.pdf.

[44] Von Krogh, G., \& Roos, J. (1995). Organizational Epistemology. New York:St.Martin press.

[45] Wiig, K. M. (1993). Knowledge management foundations: thinking about thinking: how people and organizations create, represent, and use knowledge. Arlington, TX: Schema Press.

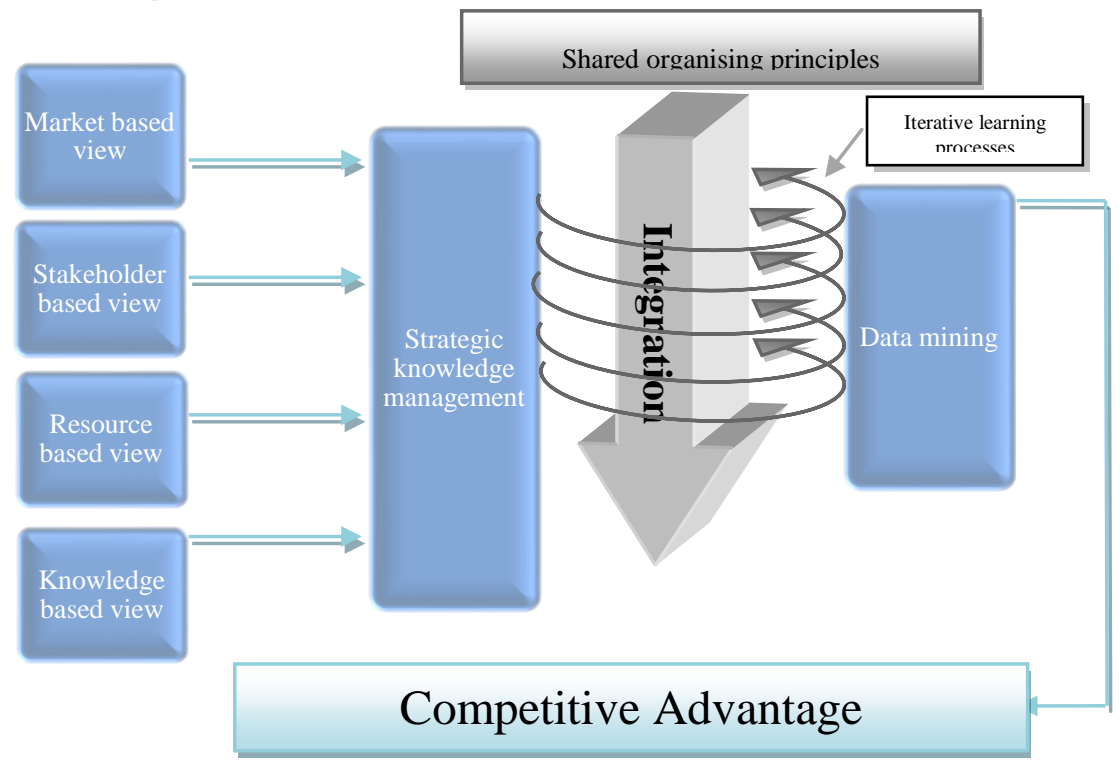

Figure 1: Creating competitive advantage through integration of Data Mining and Strategic Knowledge Management 